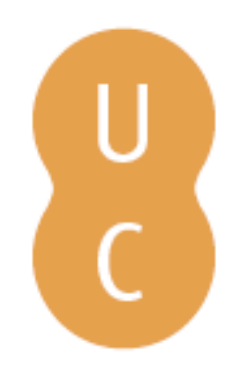

\title{
pombalina
}

\section{Advanced 3D scan data analysis for performant reengineering maintenance processes}

\author{
Autor(es): $\quad$ Grosser, Hendrik; Stark, Rainer \\ Publicado por: Tecnologia da Universidade de Coimbra, Departamento de Engenharia \\ Mecânica \\ URL $\quad$ URIstente: $\quad$ URItp://hdl.handle.net/10316.2/33319 \\ DOI: $\quad$ DOI:http://dx.doi.org/10.14195/978-972-8954-42-0_11 \\ Accessed : $\quad$ 26-Apr-2023 14:43:02
}

A navegação consulta e descarregamento dos títulos inseridos nas Bibliotecas Digitais UC Digitalis, UC Pombalina e UC Impactum, pressupõem a aceitação plena e sem reservas dos Termos e Condições de Uso destas Bibliotecas Digitais, disponíveis em https://digitalis.uc.pt/pt-pt/termos.

Conforme exposto nos referidos Termos e Condições de Uso, o descarregamento de títulos de acesso restrito requer uma licença válida de autorização devendo o utilizador aceder ao(s) documento(s) a partir de um endereço de IP da instituição detentora da supramencionada licença.

Ao utilizador é apenas permitido o descarregamento para uso pessoal, pelo que o emprego do(s) título(s) descarregado(s) para outro fim, designadamente comercial, carece de autorização do respetivo autor ou editor da obra.

Na medida em que todas as obras da UC Digitalis se encontram protegidas pelo Código do Direito de Autor e Direitos Conexos e demais legislação aplicável, toda a cópia, parcial ou total, deste documento, nos casos em que é legalmente admitida, deverá conter ou fazer-se acompanhar por este aviso.

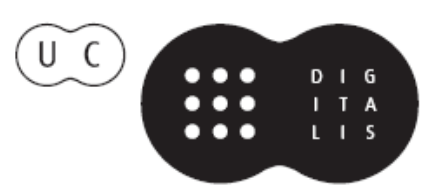




\title{
Advanced 3D Scan Data Analysis for performant Reengineering Maintenance Processes
}

\author{
Hendrik Grosser ${ }^{1}$; Rainer Stark ${ }^{1,2}$ \\ ${ }^{1}$ hendrik.grosser@ipk.fraunhofer.de; ${ }^{2}$ rainer.stark@ipk.fraunhofer.de \\ ${ }^{1,2}$ Division of Virtual Product Creation, Fraunhofer IPK Berlin \\ Berlin, Germany \\ ${ }^{2}$ Chair of Industrial Information Technology, TU Berlin \\ Berlin, Germany
}

\begin{abstract}
Overhaul processes of long-living, cost-intensive machines and facilities are time-consuming tasks. They aim either at full recovery of the original product condition through repair or spare part exchange or at modernization for performance enhancement. However, decision for an overhaul should be carefully considered, because realization may be difficult und time-critical. Every overhaul process is unique and based on a thoroughly diagnosis of product condition. This makes it a risky and hard to plan project. In this context speed of overhaul operation is essential for avoiding costs due to machine down times. Obsolescence of components and modernization goals demand for an efficient reengineering to design geometric models for production. Modern 3D scanning technologies deliver 3D models of actual product geometry and allow deviation and tolerance analyses in case of available reference models. However, optical limitations and difficult part disassembly make 3D digitization still a laborious task and is additionally followed by a high effort in data post-processing. This paper depicts a new approach to facilitate reengineering processes through advanced methods in 3D scan data analysis of non-disassembled products. Implementations allow parts identification in 3D assembly scans through shape recognition and database search for provision of needed $\mathrm{CAD}^{1}$ data.
\end{abstract}

Keywords-Maintenance; overhaul; inspection; reengineering; $3 D$ scan; shape retrieval.

\section{INTRODUCTION}

Reengineering in general means to revise or rework something with the aim of performance enhancement or adaptation $[1,2]$. This can be related to products or processes like mechanical, electrical or software designs as well as business, design or lifecycle processes. This paper focusses on reengineering of long-living products with high investment costs, e. g. steam turbines, jet engines, turbo chargers, means of transportation (air crafts, trains, ships), factory plants, machine tools and engines. Operating times are between twenty and fifty years. These types of products are predominantly custommade items that are adapted to customer's needs. In case of steam turbines an adaptation to customer's factory design with specific parts, piping and placement next to related machines and facilities has to be realized. Individualization is a big problem for maintenance tasks, because maintenance companies are not able to develop standardized processes of inspection, meaning functionality checking and error search as well as spare part selection. Basis of the inspection process is the identification of build in parts which can be a timeconsuming task. Parts have to be disassembled and labels and geometries have to be compared with part data bases manually. Maintenance companies struggle with wear-induced difficult disassembly and label reading and the diversity of variants. In most difficult maintenance tasks technical documents like bill of material and design drawings or data as well as maintenance protocols are not available. This issue happens if the maintenance company is not the original equipment manufacturer (OEM). An additional issue occurs if spare parts are no longer available, because suppliers quit production or their business due to economic reasons. In this case parts have become obsolete and machine owners have to reengineer and remanufacture equivalent or similar parts in order to continue machine operation. The worst case appears if functionality of a whole obsolete system (e. g. a control station) cannot be understood sufficiently for maintenance purposes. In this case the complete system has to be reengineered. Another need for reengineering appears if aging machines cannot keep up with state of the art machines in terms of performance or efficiency and an overhaul is the most economical solution to stay competitive. However, costs of overhaul processes which are always unique projects are hard to determine. In addition they are time critical, because machine downtimes are linked with high financial loss for the owner. Overhaul processes comprise all mentioned reengineering issues of parts design, system design and modernized design so that these processes will be analyzed in more detail in the following. Automation of reengineering processes is a challenge of the future. Therefore $3 \mathrm{D}$ product data of existing products to be overhauled is needed and has to be acquired by a reverse engineering process. In this case it means the process from acquisition of $3 \mathrm{D}$ scan data to modifiable CAD models.

${ }^{1} \mathrm{CAD}$ - Computer Aided Design 


\section{OVERHAUL PROCESS ANALYSIS}

Overhaul processes are being performed in the service phase of the product life cycle. They are unplanned and will be necessary after several years of product use and maintenance (e. g. after 10 to 30 years). Fig. 1 shows the generic overhaul process. The first step after machine decommissioning is preinspection with the goal to determine product condition without disassembly. If technical documentation is available all documents are worked through and the product will be visually checked. In case of turbines boroscopes are being used to inspect inner components. In order to proceed with inspection parts have to be disassembled, cleaned and identified by manual search in data bases or parts catalogues as mentioned above. In the inspection phase optical, electrical and tactile measurement principles deliver precise data and allow a deviation analysis with nominal or desired condition. 3D scanning sensors are used for acquisition of geometric data. Additionally, functional principles of the product are clearly described and components or systems for substitution or modernization have been identified. Operation scheduling aims for planning of resources like staff, IT usage or working times. Reengineering is based on 3D scan data of the current product's parts, components and installation space as well as on original CAD data from the $\mathrm{OEM}^{2}$. However, as reasoned above the latter is hardly available. The digitization process is based on 3D point coordinates measured by a 3D sensor. These point clouds are post processed to a polygon model and afterwards to a constructed solid geometry (CSG) which can be modified with CAD systems. After design engineers have developed new parts and components resources have to be determined for the production schedule. Due to production tolerances remanufactured products have to go through a quality check which means to apply again the mentioned measurement equipment. Especially 3D scanning allows a fast process for geometrical deviation analysis because reference data from the reengineering phase does already exist. Then, all parts and components can be reassembled to proof machine performance by test runs. Finally, machine is handed out to the owner for recommissioning. The whole process is supported by product data management and document management systems.

From the beginning of the overhaul process information and data is compiled or created. This sub-process is individual to every machine and there is no standardized practice which allows determining exact effort and costs of this sub-process. If retrieval of information about parts concerning their original design intend (e. g. tolerances or system functionality) was not successful reengineering becomes more difficult. In this case engineers have to reinvent parts and components that realize the original purpose of the machine and additionally achieve higher efficiency. Preparation of simulation models and even prototypes for testing might be necessary. This kind of reengineering process with subsequent production and testing equals the engineering process of life cycle's design stage. Consequently, on this part of the overhaul process there is no specific optimization potential. Improvement concerns work on methodologies, collaboration and concurrent engineering, product data management (PDM), CAD performance and IT system interoperability which covers a large field of research activities that are already running. Hence, this paper focusses on the inspection and digitization issues which aim for part information and data retrieval with the goal of better preparation of the reengineering stage through an automation approach. Conclusion: time reduction in the data retrieval phase leads to time reduction of reengineering und thus has the highest potential for improvement of overhaul processes.

\section{SOLUTION APPROACH}

The reengineering stage needs as an input $3 \mathrm{D}$ product models in the form of constructive solid geometry (CSG). This comprises single parts, components and assemblies as well as the whole product with its installation spaces. Two types of 3D geometry models are needed: geometry of the real product (as-is condition) and of the original design (as-designed condition). Due to wear both conditions can be crucially different. Furthermore, information in the form of a bill of material (BOM) and an inspection report is needed including

- Part or component name

- $\quad$ ID code

- Part quantity

- Materials

- As-is condition compared to as-designed condition.

The earlier this information and geometric data is retrieved in the overhaul process the faster the reengineering stage can be started. Thus, research aims to get more information and data out of the pre-inspection stage. This information shall be used by engineers for subsequent understanding of whole system functionality, single operating principles and necessary tolerances for production.

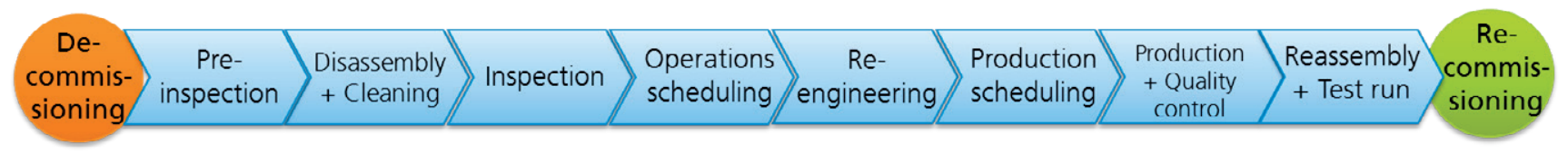

Product data management + Document management

Fig. 1. Generic overhaul process.

${ }^{2}$ OEM - Original Equipment Manufacturer 


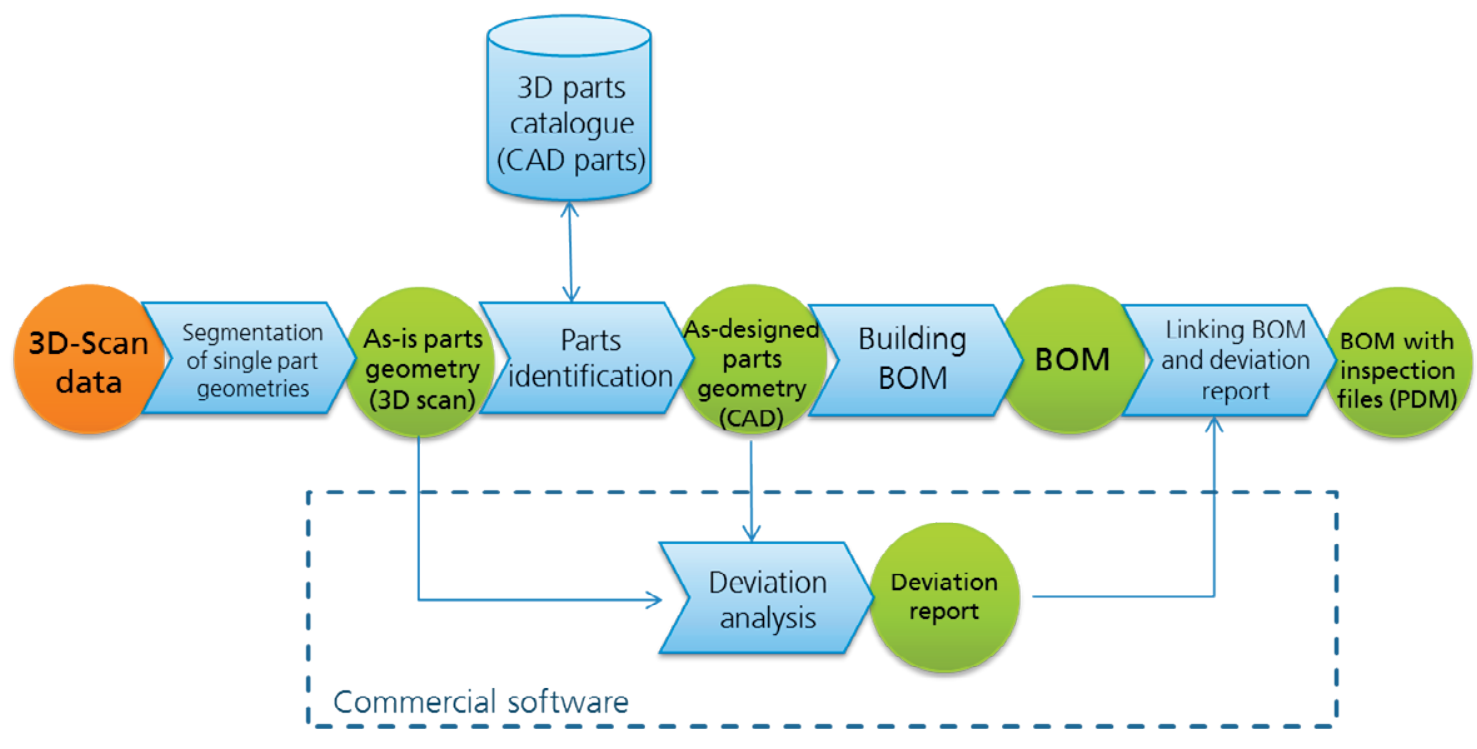

Fig. 2. Process to be realized with the reengineering cokpit.

With the goal to achieve a high degree of automation a 3D scanning and post-processing process will be invented and a test implementations has to be done. Fig. 2 shows how 3D scan data shall be processed with the new process to automate generation of product BOM and to add a damage report. Since this process is part of the pre-inspection stage of the overhaul process products will be digitized without disassembly. Future 3D scanning, X-ray and boroscope solutions may allow digitizing not only of the outer surface but also of inner and hidden structures. The process of Fig. 2 may also be beneficial with acquisition of only outer surface geometry. Once the digital geometry model has been created by standard reverse engineering methods as a polygon model (e. g. in the common STL format) it will be imported in a shape retrieval application to be developed. This application provides intelligent algorithms that are able to detect geometry of single parts and to separate them from each other. In case only 3D scanning was used to digitize outer surface this sub-process delivers single part geometries which are incomplete. However, the more complete the surface the easier will be the next step of parts identification which shall be automatically performed by a geometrical similarity search. This shape search is based on self-defined footprints or so called descriptors. A mathematical calculation delivers such a descriptor for any part geometry. Then, part geometries can be compared to other part geometries in a data base by comparing their descriptors provided that the data base allowed it to calculate such descriptors. Shape search delivers a priority list of similar geometries respectively parts and calculates a percentage that indicates their matching rate. Found parts will be extracted from the data base and saved separately together with data base information about parts name, ID and materials if available.

Parts from open source online data bases or commercial parts catalogues are representing as-designed CAD geometry (CSG files) whereas 3D scans deliver the as-is geometry. In the next step matching part files can now be compared by a deviation analysis with commercial software. The result will be a graphical report which shows deviations of part's surfaces with a color scale. Colors can indicate e. g. if as-is part's geometry runs out of tolerance. Thus, for maintenance purposes it can be used as a damage report.

In the next step information about product's BOM will be stored in an $\mathrm{XML}^{3}$ file and linked with damage reports and 3D data files. Finally, the XML file can be imported in a $\mathrm{PDM}^{4}$ system that allows robust data management. This allows engineers to understand product condition and gives hint about operational principles. Finally, engineers can start with their creative process of designing for the overhaul processes. It may be necessary to transform the polygon data by the $3 \mathrm{D}$ scans into $\mathrm{CAD}$ files (CSG files) with commercial reverse engineering tools.

\section{SHAPE RETRIEVAL SYSTEM}

Recent work dealt with approaches of mesh segmentation as well as with gray scale segmentation in voxel data $[3,4]$. In addition this paper focuses on the identification of single parts presenting a new approach. This approach aims for a geometrical similarity search of 3D scanned parts with parts of a data base.

\section{A. Related research work and applications}

Main components of a shape retrieval system are a mathematical descriptor for geometry and a data base with reference models. In addition an evaluation principle for performance evaluation of descriptors can be used. A very famous evaluation principle is offered by the Princeton Shape Benchmark (PSB) [5]. However, it was not used because the according data base does not include mechanical parts. This is

\footnotetext{
${ }^{3}$ XML - Extensible Markup Language

${ }^{4} \mathrm{PDM}$ - Product Data Management
} 
important, because for test series geometry of data base parts should be very similar to 3D scanned parts. More suitable is the Engineering Shape Benchmark (ESB) which consists of mechanical parts [6].

Demo shape retrieval systems are available on the websites of Princeton University [7] and the Informatics \& Telematics Institute [8]. Part search is possible through input of 2D or 3D sketches and text. The companies TurboSquid, GrabCAD and CADENAS offer free online data bases for 3D geometry parts search. CADENAS PARTsolutions is the most interesting due to mechanical parts catalogues [9]. This data base has been designed to search for CAD parts. Research has shown that it is also suitable for 3D scan data, but with some limitations [4]. No retrieval system could be found that allowed a partial matching meaning search for incomplete $3 \mathrm{D}$ scanned geometry of parts.

\section{B. Procedure of part identification}

A shape retrieval system was designed through adaptation of the system of Funkhouser et. al. [10] by combining shape variant and invariant descriptors (Fig. 3). Size invariant descriptors are favored to size variant (respectively geometric) descriptors due to better matching rates and faster processing times. However, in this case shape variant descriptors enable a preselection by sorting according to dimensions, focal point, volume and surface.

The adapted shape retrieval procedure starts with a $3 \mathrm{D}$ model of a single part that was segmented out of a point cloud (query object). Firstly, a size variant descriptor is calculated for this object and the reference objects of a data base. Then, size of the query object is compared with reference objects by using bounding boxes or convex hulls which enables calculating distances of the descriptors. After sortation $\mathrm{n}$ best data base models are shown to the user whereas $2 \mathrm{n}$ descriptors are used for further processing. The second step is comparison between calculated size invariant descriptors of query objects and data base objects. Resulting distances will be sorted again and finally $n$ best data base models are shown to the user.

\section{Definition of a feature descriptor}

Query objects coming from 3D mesh segmentation have no closed surface and thus are hard to compare with CAD data models of a data base. For comparison it is necessary to normalize their size, position and rotation. Analyses of existing descriptors showed that no existing descriptor alone was able to deliver satisfying results. Hence, different descriptors were combined respectively correlated. Thereunder were geometrical descriptors as well as scaling invariant descriptors (TABLE 2 and TABLE 3). The following restrictions were considered when analyzing and selecting descriptors for test series:

- Information about object sizes had to be included

- No precise description of surface which would hinder partial matching

- Standard PCA (Principal Component Analysis) algorithm by Vranic et. al. [11] is deficient for normalization of rotation

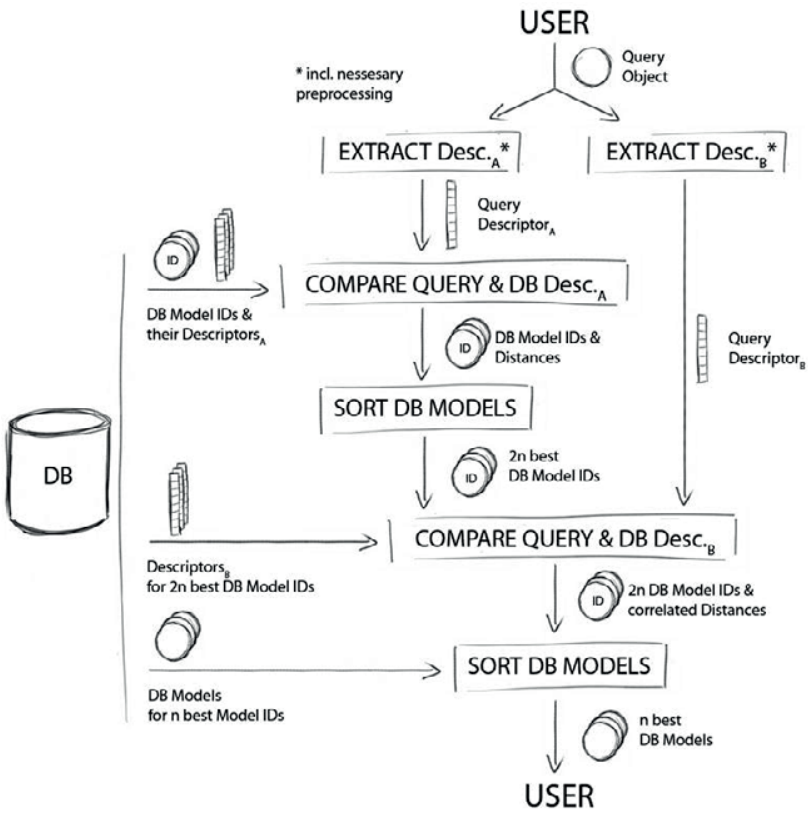

Fig. 3. Procedure of part identification. Descriptor A is size variant whereas descriptor B is size invariant.

\section{Set up of test data base and query objects}

A test data base was set up with parts from Engineering Shape Benchmark (ESB), CADENAS PARTsolutions and with own 3D scanned parts of a car generator which were segmented with own segmentation principles in previous work [4]. TABLE 1 shows all reference parts and numbers of subjectively assessed similar objects. For some query objects variants have been used (Fig. 4).

TABLE 1. DATA BASE MODELS AND QUERY OBJECTS

\begin{tabular}{|c|c|c|}
\hline $\begin{array}{l}\text { Reference models } \\
\text { in data base (CAD) }\end{array}$ & $\begin{array}{l}\text { Variants of } \\
\text { corresponding } \\
\text { query object (3D } \\
\text { scan) }\end{array}$ & $\begin{array}{c}\text { similar objects } \\
\text { (subjectively } \\
\text { assessed) }\end{array}$ \\
\hline Generator housing & 4 & 15 \\
\hline Bearing Bracket & 4 & 5 \\
\hline Fan & 4 & 13 \\
\hline Pulley & 4 & 13 \\
\hline Slip ring & 1 & 15 \\
\hline Stator & 3 & 16 \\
\hline Blade & 1 & 2 \\
\hline Block & 1 & 8 \\
\hline Gearbox plate & 1 & 8 \\
\hline Impeller 1 & 1 & 14 \\
\hline Impeller 2 & 1 & 12 \\
\hline $\begin{array}{l}\text { Impeller } 3 \\
\text { (ceramic) }\end{array}$ & 1 & 18 \\
\hline Piston & 1 & 13 \\
\hline Turbine & 1 & 7 \\
\hline$=14$ & $=28$ & $=159$ \\
\hline
\end{tabular}




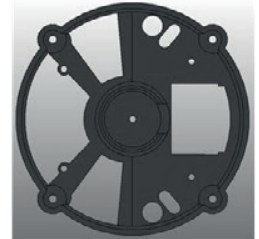

(a) CAD model (reference)

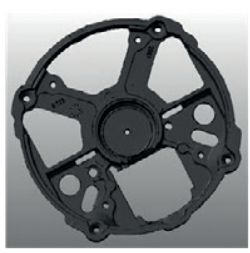

(b) 3D scan

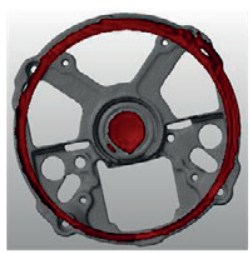

(c) Manually segmented CT

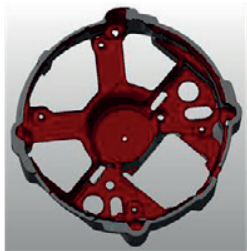

(c) Manually segmented 3D scan

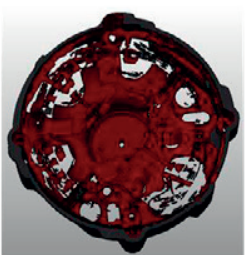

(d) Automated 3D scan segmentation
Fig. 4. Variants of generator housing.

\section{E. Test series}

Separate test series for geometric and scaling invariant descriptors as well as correlated descriptors from both groups were performed. Comparison was made through calculation of average precision (AP) respectively ranks:

$$
A P=\frac{1}{m} \sum_{k=1}^{m} \operatorname{Precision}\left(R_{k}\right)=\operatorname{Precision}\left(R_{1}\right)=\frac{1}{\text { Rank }_{1}}
$$

$\mathrm{m}=$ number of relevant results

$\mathrm{R}_{\mathrm{k}}=$ set of ranked retrieval results till the $\mathrm{k}^{\text {th }}$ relevant result

The mean for APs of all query objects is

$$
m A P=\frac{1}{Q} \sum_{j=1}^{Q} A P_{j}
$$

Due to the fact that there is only one fitting reference object in the data base equation (2) can be simplified and resolved to mean Rank $(\mathrm{mR})$ which allows quantitative comparison of queries:

$$
m R=\frac{1}{Q} \sum_{j=1}^{Q} \operatorname{Rank}_{j}
$$

TABLE 2TABLE 2, TABLE 3TABLE 3 and Fig. 5 show mean Ranks for all query objects for the popular L1 and L2 metrics:

$$
\begin{array}{ll}
\text { L1-Metric: } & d(x, y)=\sum_{i=1}^{n}\left|x_{i}-y_{i}\right| \\
\text { L2-Metric: } & d(x, y)=\sqrt{\sum_{i=1}^{n}\left(x_{i}-y_{i}\right)^{2}}
\end{array}
$$

These metrics calculate distances for $3 \mathrm{D}$ vectors pointing to objects points and thus allow comparison of descriptors by calculation of point distances.

Test series for geometric descriptors showed that the descriptor for the surface obtained the best results followed by descriptors for dimension and Bounding Box. Metrics L1 and L2 were close together so that it makes no big difference which one has been chosen for comparison. Down sampling of voxel grid caused only for the barycenter descriptor a slightly better result whereas all other values were slightly worse (TABLE 2).

TABLE 2. MEAN RANKS FOR GEOMETRIC DESCRIPTORS.

\begin{tabular}{|l|c|c|c|c|}
\hline \multirow{2}{*}{ Descriptor } & \multicolumn{2}{|c|}{ Original } & \multicolumn{2}{c|}{ After downsampling } \\
\hline $\begin{array}{l}\text { Bounding } \\
\text { Box }\end{array}$ & 8,39 & 9,54 & 8,46 & 9,79 \\
\hline Dimension & 6,29 & 6,96 & 6,89 & 7,11 \\
\hline $\begin{array}{l}\text { Dimension } \\
\text { sorted }\end{array}$ & 6,75 & 7,29 & 7,25 & 7,71 \\
\hline $\begin{array}{l}\text { Barycenter } \\
\text { Volume }\end{array}$ & 11,89 & 12,00 & 11,14 & 12,18 \\
\hline Surface & 9,54 & 9,54 & - & - \\
\hline $\begin{array}{l}\text { Volume/ } \\
\text { surface }\end{array}$ & $\mathbf{5 , 8 9}$ & $\mathbf{5 , 8 9}$ & - & - \\
\hline
\end{tabular}

Test series for scaling invariant descriptors for different voxel sizes $(8,16,32$ and 64) showed that the Spherical Harmonics Descriptors (SHD) delivers best results (but was only applicable for a voxel size of 64) followed by Point Distance Distribution (PDD). PDD delivered best results for voxel size 16 and the Vector Descriptor (VD) for size 32 (TABLE 3). 
TABLE 3. MEAN RANKS FOR SCALING INVARIANT DESCRIPTORS.

\begin{tabular}{|c|c|c|c|c|c|c|c|c|}
\hline \multirow{2}{*}{ Descriptor } & \multicolumn{2}{|c|}{$8 \times 8 \times 8$} & \multicolumn{2}{|c|}{$16 \times 16 \times 16$} & \multicolumn{2}{|c|}{$32 \times 32 \times 32$} & \multicolumn{2}{|c|}{$64 \times 64 \times 64$} \\
\hline & L1 & L2 & L1 & L2 & L1 & L2 & L1 & L2 \\
\hline $\begin{array}{l}\text { Spherical } \\
\text { Harmonics } \\
\text { Descriptor } \\
\text { (SHD) }\end{array}$ & - & - & - & - & - & - & - & 7,00 \\
\hline $\begin{array}{l}\text { Point } \\
\text { Distance } \\
\text { Distribution } \\
\text { (PDD) }\end{array}$ & 20,10 & 19,18 & 18,61 & 18,64 & 29,58 & 30,2 & - & - \\
\hline $\begin{array}{l}\text { Voxel } \\
\text { Descriptor } \\
\text { (VD) }\end{array}$ & 26,71 & 26,61 & 19,21 & 19,25 & 16,04 & 16,82 & 16,86 & - \\
\hline
\end{tabular}

When combining geometrical descriptors with scaling invariant descriptors mean Rank values could be lowered to 2.46. This result was achieved by experimental setting of weights for the six chosen descriptors depicted in Fig. 5.

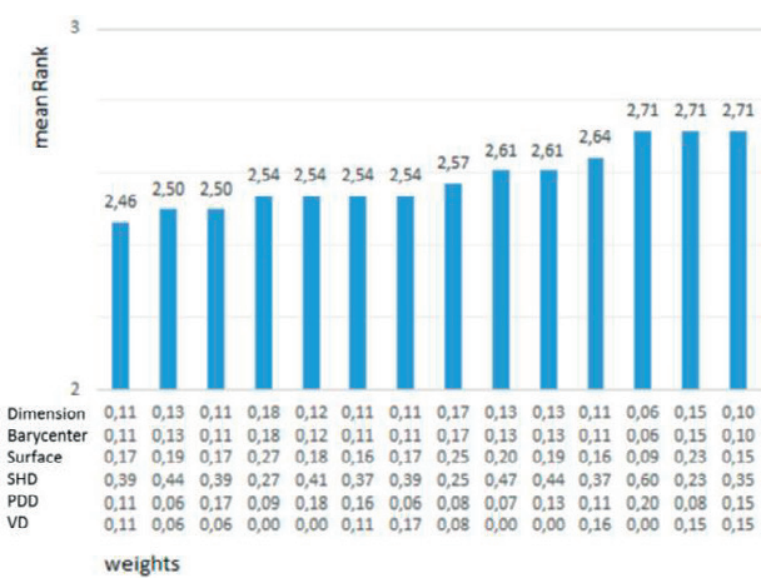

Fig. 5. Mean Ranks of weighted combinations of six chosen descriptors.

\section{GRAPHICAL USER INTERFACE (GUI)}

The Point Cloud Library (PCL) [12] was used as the framework for implementation of the shape retrieval system and Qt [13] enabled the realization of the Graphical User Interface (GUI).

The implemented GUI (Fig. 6) allows to load query objects (e. g. 3D scanned parts) (A) and to visualize them $(\mathrm{G})$. The maximum number of found priorities can be set with toolbar (C). Toolbar (F) enables configuration of descriptors. Six descriptors can be chosen, combined and weighted. Metrics can be defined for evaluation with (E). Button (D) starts the identification procedure.

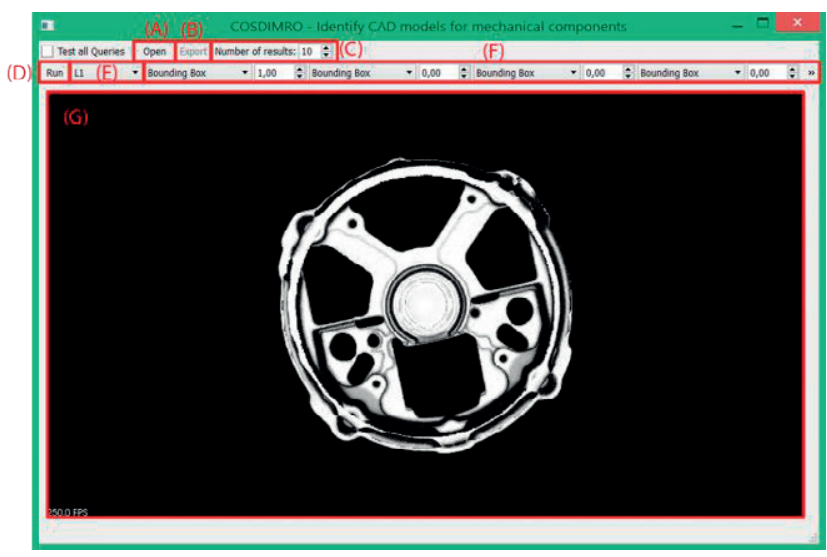

Fig. 6. GUI with loaded query object and parameters for configuration.

When the comparison of the query object with the data base parts is finished a priority list shows best matches with a percentage (I) (Fig. 7). Similarity is defined as:

Similarity $=1-$ Distance

Similarity in $\%=$ Similarity $* 100$

For combined and weighted descriptors diagram $(\mathrm{H})$ shows deviations of each single descriptor of the query object to its corresponding reference descriptor. Status bar $(\mathrm{J})$ names the rank of the selected parts and button (B) provides an export function.

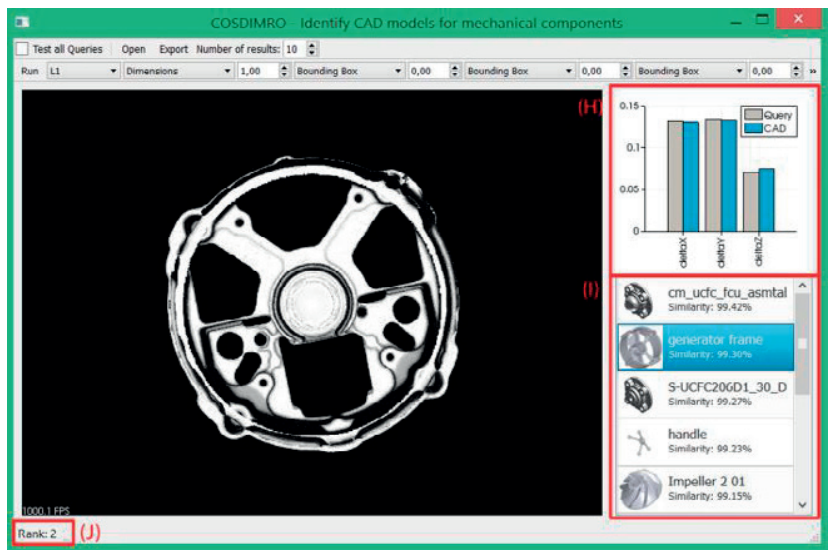

Fig. 7. Identification result with priority parts list and similarity value.

The user can open another screen (Fig. 8) for additional analysis of rank distribution (K). Query objects can be selected with drop down box (L). Bar chart (M) shows calculated ranks of each single query object with an own color. Status bar (N) depicts the mean Rank. This analysis tool enables calculation of mean Ranks for individual compositions of descriptors and weights. 


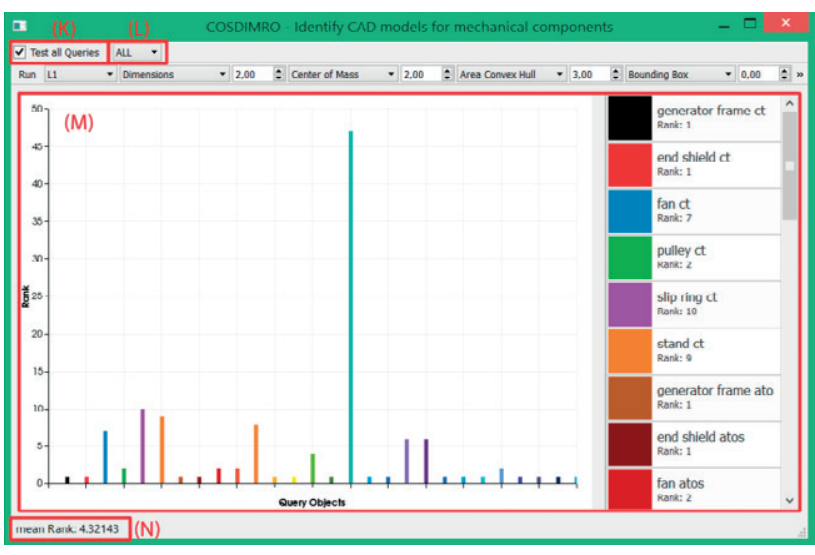

Fig. 8. Analysis tool for calculation of individual mean Ranks.

\section{CONCLUSION AND OUTLOOK}

Results for test data set were very promising. Every query object could be identified. Only some difficulties appeared when comparing a manually designed and simplified CAD model (electric stator) with a 3D scan (Fig. 9).
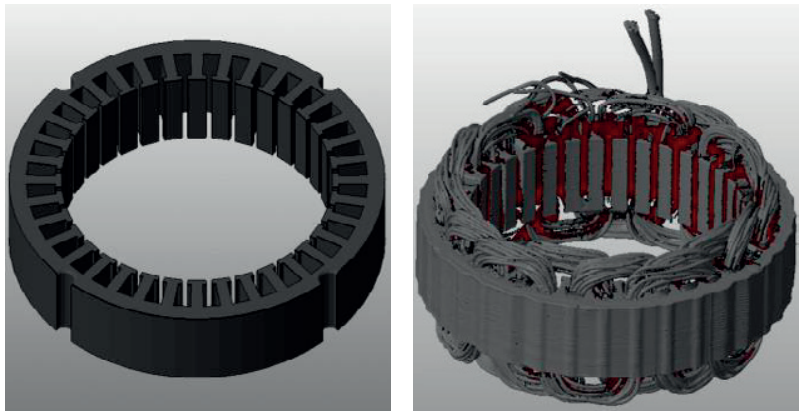

Fig. 9. CAD model (left) and 3D scan of an electric stator (right).

Further test series with a bigger data base and more test objects have to be made to quantify industrial relevance for the presented shape retrieval application. In addition, analysis of common geometrical differences between as-designed CAD objects and as-is scan objects could improve definition of descriptor selection and weighting. The manual combination and weighting of descriptors is time-consuming and needs experience. Classification of geometric features could enable automated pre-selection of appropriate descriptors and their correlation. Furthermore, identification results are dependent on alignment of query and CAD object. Thus, improvement of alignment or overlay method could be very beneficial. For object comparison distances of single 3D coordinates were calculated by a time-consuming brute force method so that a more intelligent calculation can improve processing time and would enable efficient search in large data bases.

Future research aims to realize automated generation of BOMs with linking to damage reports as depicted in Fig. 2. This principle shall afterwards be integrated in the more comprehensive concept that was presented in [4]. Work will also comprise approaches for integration of part segmentation in $3 \mathrm{D}$ scanned assembly models and identification. Therefore, CAD parts from a data base shall be directly fitted into assembly point clouds through a pattern matching algorithm. A 3D scan of a used helicopter gas-turbine (Klimov GTD-350) will be used as test object (Fig. 10).

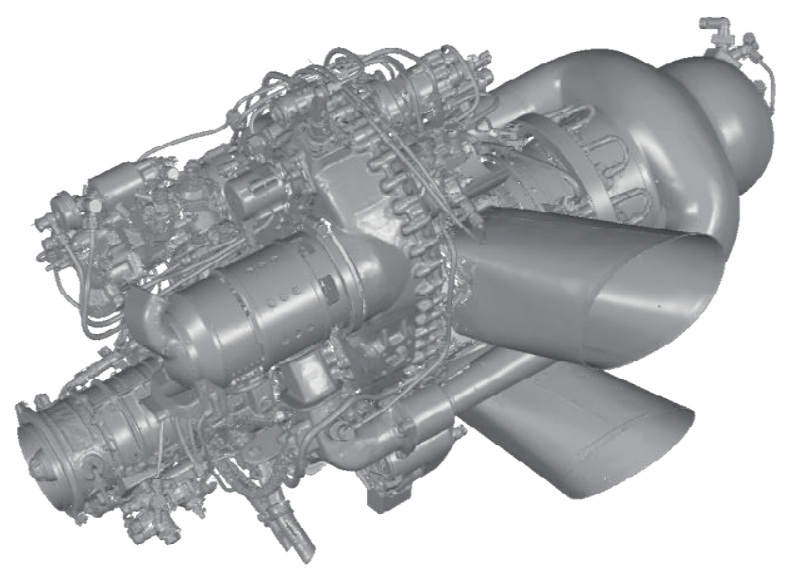

Fig. 10. 3D scan (polygon model) of the helicopter gas-turbine Klimov GTD350 .

\section{ACKNOWLEDGEMENT}

This research was facilitated by the work of Anja Sonnenberg and Kai-Uwe Barthel of the Beuth Hochschule für Technik Berlin. Furthermore it was supported by the senate administration of Berlin (Senatsverwaltung für Bildung, Wissenschaft und Forschung) and funded by the European Union with EFRE means.

\section{REFERENCES}

[1] Meriam Webster Online Dictionary. Available: http://www.merriamwebster.com/dictionary/reengineering (8th June 2014).

[2] The Free Dictionary. Available:

http://www.thefreedictionary.com/reengineering (6th June 2014).

[3] H. Grosser, B. Beckmann-Dobrev, F. Politz, and R. Stark, "Computer Vision Analysis of 3D Scanned Circuit Boards for Functional Testing and Redesign," Procedia CIRP, vol. 11, pp. 229-233, 2013.

[4] R. Stark, H. Grosser, and P. Müller, "Product analysis automation for digital MRO based on intelligent 3D data acquisition," CIRP Annals Manufacturing Technology, vol. 62, no. 1, pp. 123-126, 2013.

[5] P. Shilane, P. Min, M. Kazhdan, and T. Funkhouser, "The princeton shape benchmark," in Proceedings Shape Modeling Applications, 2004, pp. 167-388.

[6] S. Jayanti, Y. Kalyanaraman, N. Iyer, and K. Ramani, "Developing an engineering shape benchmark for CAD models," Computer-Aided Design, vol. 38, no. 9, pp. 939-953, 2006.

[7] Princeton Shape Retrieval \& Analysis Group, 3D Model Search Engine. Available: http://shape.cs.princeton.edu/search.html (12th June 2014).

[8] Informatics \& Telematics Institute, 3D Search. Available: http://3dsearch.iti.gr/3DSearch (12th June 2014).

[9] CADENAS Konstruktions-, Softwareentwicklungs- und Vertriebs GmbH, 2D and 3D CAD Models: Manufacturer Catalogs. Available: http://b2b.partcommunity.com/community/ (12th June 2014).

[10] T. Funkhouser, P. Min, M. Kazhdan, J. Chen, A. Halderman, D. Dobkin, and D. Jacobs, "A search engine for 3D models," ACM Trans. Graph, vol. 22, no. 1, pp. 83-105, 2003. 
[11] D. V. Vranic, D. Saupe, and J. Richter, "Tools for 3D-object retrieval: Karhunen-Loeve transform and spherical harmonics," in 2001 IEEE Fourth Workshop on Multimedia Signal Processing, pp. 293-298.

[12] Point Cloud Library (PCL). V1.6. Available: http://pointclouds.org/ (12th June 2014).

[13] Qt. V4.8. Available: http://qt-project.org/ (12th June 2014). 